\title{
Biomimetic Coating on Polymeric Implant Surfaces -The Need of a Quality Standard
}

\author{
Dietmar Schaffarczyk ${ }^{1 *}$, Andreas Schwitalla ${ }^{2}$ and Stefan Leonhardt ${ }^{3}$ \\ ${ }^{1}$ Lead Auditor for Medical Devices, stimOS GmbH, Germany \\ ${ }^{2}$ Department of Prosthodontics, Charité, University of Berlin Germany \\ ${ }^{3}$ Kumovis GmbH, Germany
}

Submission: July 20, 2020; Published: July 27, 2020

*Corresponding author: Dietmar Schaffarczyk, Lead Auditor for Medical Devices, stimOS GmbH, Germany

Keywords: Peek; Polimer; Coating; Abrasion; Delamination, Osseointegration; Health Risks; Nanomaterial; Nanocoating; Calcium Phosphate; Titanium; Plasma Spray Coating; Dip Coating

\section{Introduction}

Polyetheretherketone (PEEK) is a promising implant material because of its excellent mechanical characteristics. Although this polymer is a standard material in spinal applications, PEEK has the disadvantage by its relative bio-inertness [1]. This is the reason why coating technologies have built an impressive catalogue of success in many different applications: With a growing need for coating technologies to functionalize the surface of polymeric medical devices, the medical industry saw enormous growth in coating application onto medical devices. Various types of coatings technologies, coating materials and substances are available to date: Spanning from plasma spray coating technologies to dip coating techniques, from titanium or hydroxyapatite, all which enhance cell attachment onto orthopedic implants. But there are also various risks associated with the materials and methods mentioned above: amongst others, delamination, wear debris, abrasion, particle migration, infection or corrosion. Performing an exhaustive literature research and during different test setups simulating the predictable way of use of coated polymeric implants the authors have analyzed and evaluated the most common used and regulatory cleared coating materials and technologies in medical-device-applications. This paper is meant to give insights into the safety and performance characteristics of the most commonly used coating materials and methods onto polymeric implant surfaces.

\section{Analyzing safety and performance characteristics under simulated use}

Table 1: Overview of different regulatory cleared coating technologies for polymeric implant surfaces.

\begin{tabular}{|c|c|}
\hline Coating technology & Description \\
\hline $\begin{array}{l}\text { Titanium Plasma Spray } \\
\text { Coating }\end{array}$ & $\begin{array}{l}\text { Pure titanium coating applied by vacuum plasma spray process. The purity of the basic material corresponds to the } \\
\text { ISO 5832-2 implant standard. With a thickness of } 100 \text { to } 300 \text { micrometers, Titanium Plasma Spray coating contrib- } \\
\text { utes effectively to surface roughness, a good primary stability and improved osseointegration. }\end{array}$ \\
\hline Titanium Sputter Coating & $\begin{array}{c}\text { Physical vapor deposition technique, resulting in a coating layer to promote osseointegration with a thickness in the } \\
\text { 3-digit-nanometer range. }\end{array}$ \\
\hline Plasma-sprayed HA & $\begin{array}{l}\text { Thermal spray technique to produce HA layer with thickness from } 30 \text { to } 200 \mu \mathrm{m} \text { depending on the coating condition. } \\
\text { Due to its chemical identity with the mineral component of bone, hydroxyapatite ceramics (Ca5(PO4)3OH) have } \\
\text { proven they're worth as bone replacement material in recent years. }\end{array}$ \\
\hline Ti02-CaP Dip Coating & $\begin{array}{l}\text { To achieve even thinner coating layers, in the nanometer scale, TiO2-CaP Dip Coating was introduced: The implant } \\
\text { surface is masked by improved biocompatible titanium oxide, which has advantageous effects in many fields of med- } \\
\text { ical applications. At the same time, incorporated calcium ions are released to accelerate faster bone ingrowth. }\end{array}$ \\
\hline HA enhanced PEEK & $\begin{array}{l}\text { Material enhancement in spinal device technology. Hydroxyapatite (HA), a well-known osteoconductive material, } \\
\text { becomes fully integrated, within a PEEK matrix, making it available on the surfaces of a device only after processing } \\
\text { the implant material by milling. }\end{array}$ \\
\hline
\end{tabular}


Almost all commonly used coating materials and technologies suffer from debris, delimitation and abrasion. Coating technologies incorporating titanium additionally are suspected to corrode, particularly in acidic environments and to cause inflammatory reactions [2-5]. The table below summarizes the different disadvantages and drawbacks of commonly known and regulatory cleared coating technologies. The results presented here have been analyzed and evaluated by Pubmed literature searches and/ or during simulated use tests performed by the authors and/or affiliated companies and institutes (Tables 1 \& 2) (Figures 1-3).

Table 2: Overview of test methods and results to analyse safety and performance of coating technologies.

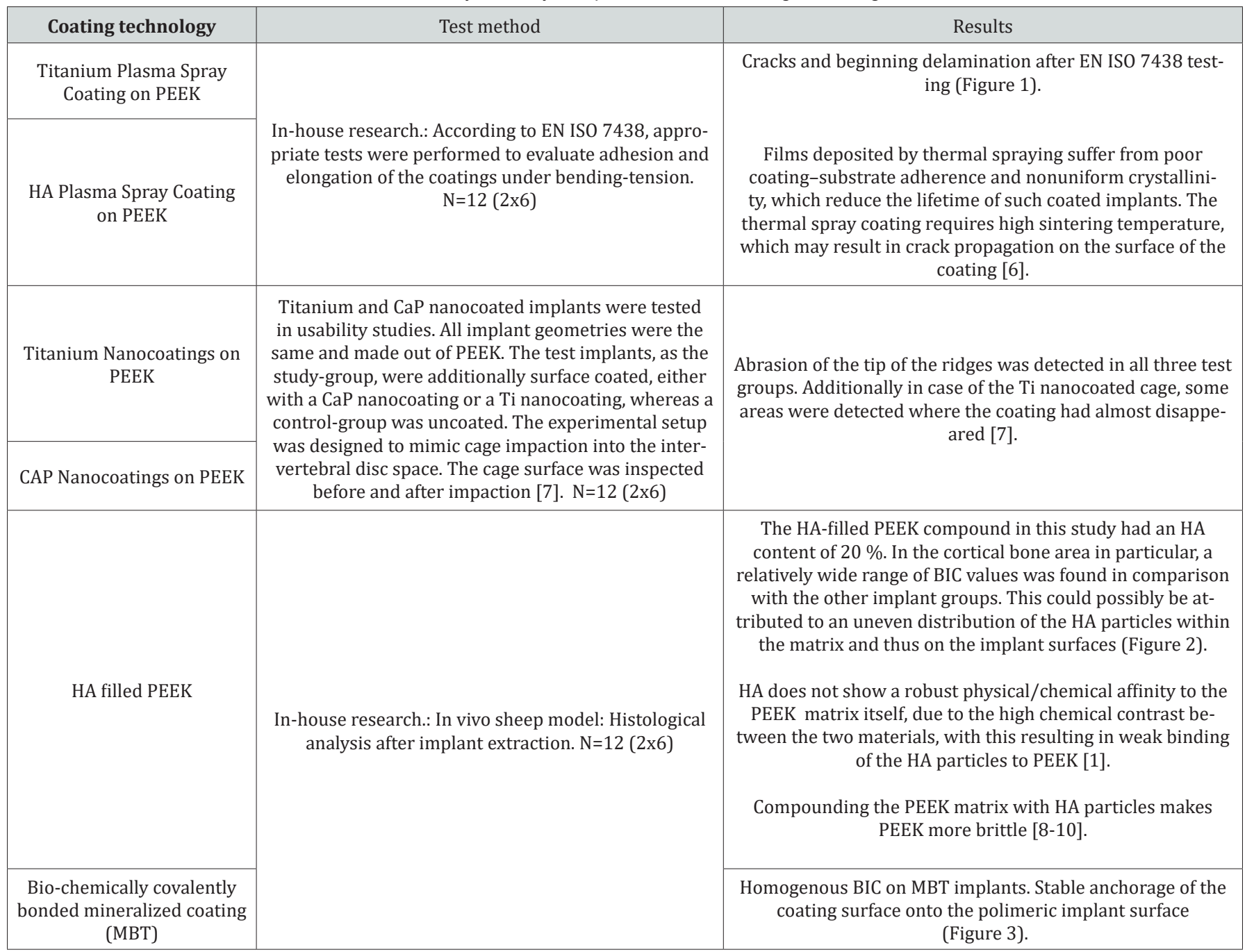

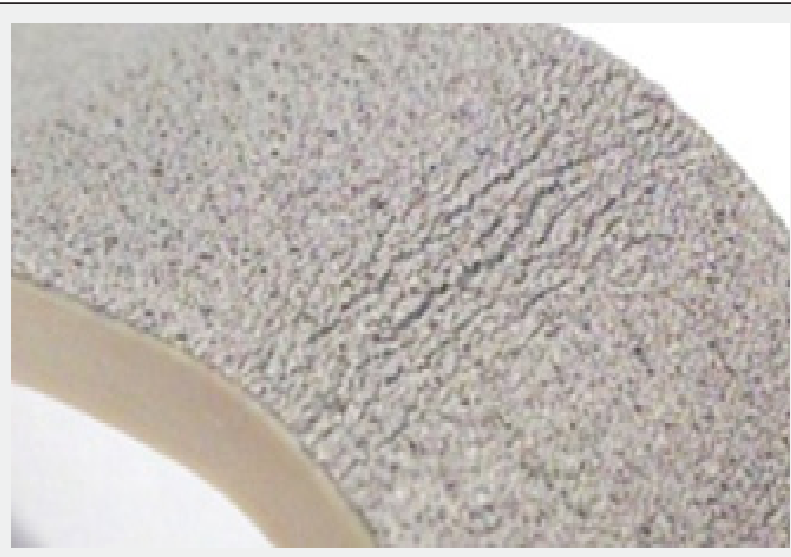

Figure 1: EN ISO 7438 bending tests of 6 plasma-spray-coated implant surfaces clearly show cracks in the coating layer. A further consequence may be delamination / abrasion. In-house research. 


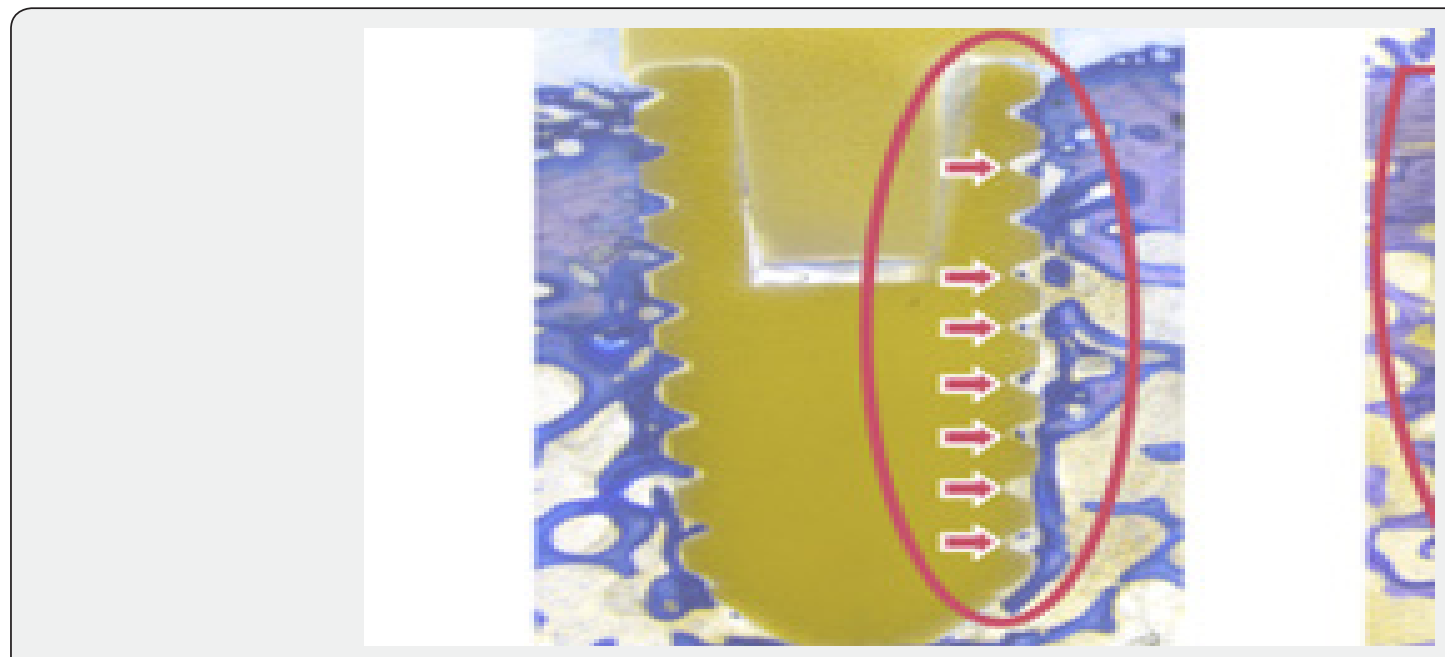

Figure 2: Histological analyzes of HA enhanced PEEK implants: Uneven distribution of HA results in an inhomogeneous BIC. In-house research.

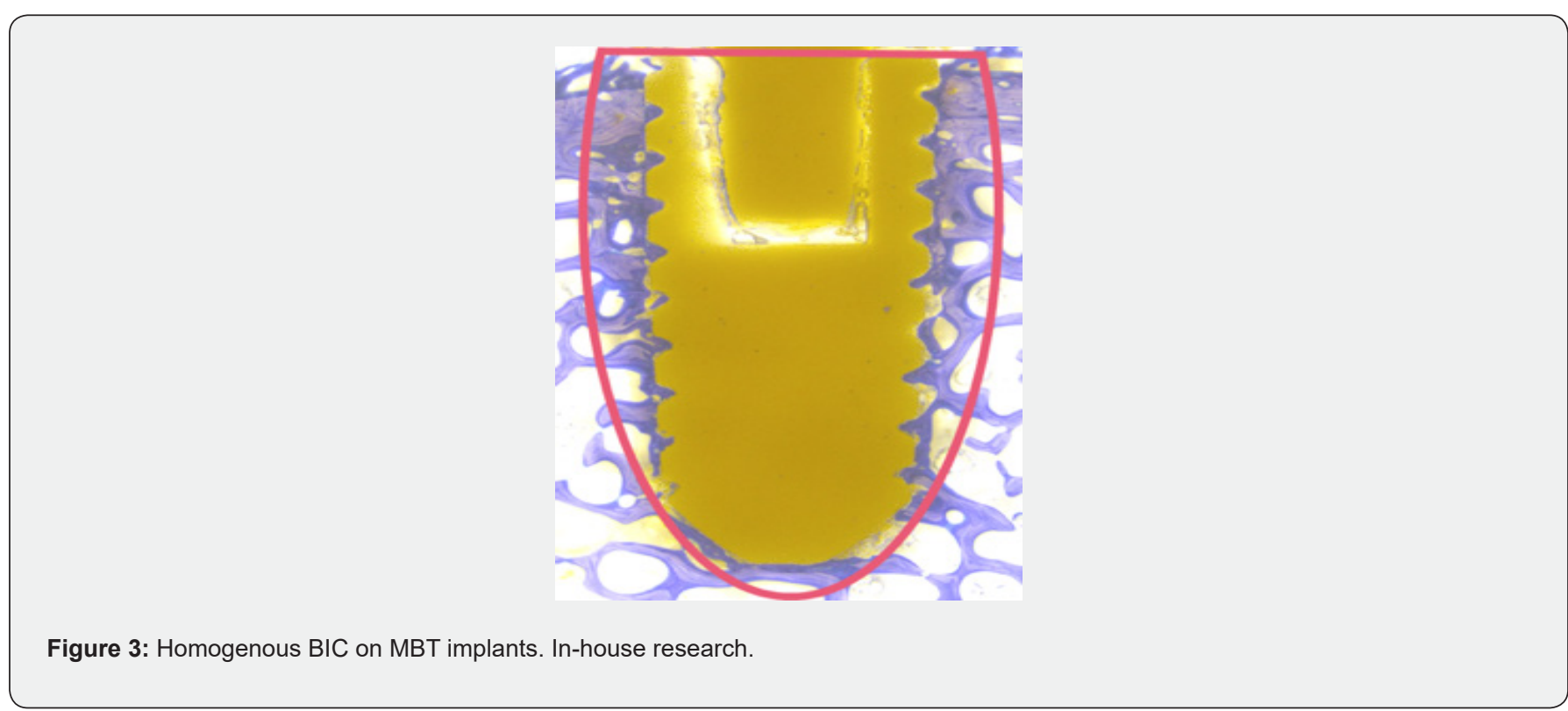

\section{Conclusion}

In vitro studies of the above mentioned coating technologies have shown encouraging results regarding osseointegration. But mechanical tests have shown the disadvantages of plasma sprayed coated surfaces, whereas coatings that incorporate titanium may corrode and result in inflammatory reactions. Coatings with a layer-thickness in a 3-digit-micrometer range may influence negatively the engineered topography of 3D-printed implants. With all these different materials and substrates used in coating applications as also due to the various coating technologies, one can get easily lost in a jungle of information: On the one hand side there are some standardized test methods to proof the mechanical stability of the coating layers on the implants surface, on the other hand these methods cannot be used to characterize the mechanical behavior of the various technologies. For biocompatibility testing different set-ups of in-vitro cell test methods and in-vivo animal models can be found in literature. The different coating materials can easily lead to a higher risk-classification of the coated implant. Different and unstructured testing methods and untransparent information may lead to wrong decisions, resulting in reduced safety and performance of polymer-implants. The authors suggest to define and establish an evaluation matrix for different surface functionalization technologies and to introduce a quality standard for coating technologies with transparent safety and performance parameters. To introduce such a quality standard will be subject of further research work, guidelines and publications.

\section{References}

1. Knaus J, Schaffarczyk D, Cölfen H (2020) On the Future Design of Bio-Inspired Polyetheretherketone Dental Implants. Macromolecular Bioscience 20(1): 1900239. 
2. Furiya Sato S, Fukushima A, Mayanagi G, Sasaki K, Takahashi N (2019) Electrochemical evaluation of the hydrogen peroxide-and fluorideinduced corrosive property and its recovery on the titanium surface. Journal of Prosthodontic Research.

3. Eliaz N (2019) Corrosion of metallic biomaterials: A review. Materials 12(3): 407.

4. Hallab NJ, Cunningham BW, Jacobs JJ (2003) Spinal implant debrisinduced osteolysis. Spine 28(20): S125-S138.

5. Kim HD, Kim KS, Ki SC, Choi Y (2007) Electron microprobe analysis and tissue reaction around titanium alloy spinal implants. Asian spine journal 1(1): 1-7.

6. Piattelli A (2016) Bone Response to Dental Implant Materials, Woodhead Publishing, UK.
7. Kienle A, Krieger A, Willems K, Wilke HJ (2019) Resistance of coated polyetheretherketone lumbar interbody fusion cages against abrasion under simulated impaction into the disc space. Journal of applied biomaterials \& functional materials $17(2)$.

8. Hughes E, Parkes A, Williams RL, Jenkins MJ, Grover LM (2018) Formulation of a covalently bonded hydroxyapatite and poly (ether ether ketone) composite. Journal of tissue engineering 9 , 2041731418815570

9. Bakar MA, Cheng MHW, Tang SM, Liao K, Khor KA, et al. (2003) Tensile properties, tension-tension fatigue and biological response of polyetheretherketone-hydroxyapatite composites for load-bearing orthopedic implants. Biomaterials 24(13): 2245-2250.

10. Tang S, Cheang P, AbuBakar M, Khor K, Liao K (2004) Tension-tension fatigue behavior of hydroxyapatite reinforced polyetheretherketone composites. International Journal of fatigue 26(1): 49-57.

\section{Your next submission with Juniper Publishers} will reach you the below assets

- Quality Editorial service

- Swift Peer Review

- Reprints availability

- E-prints Service

- Manuscript Podcast for convenient understanding

- Global attainment for your research

- Manuscript accessibility in different formats ( Pdf, E-pub, Full Text, Audio)

- Unceasing customer service

Track the below URL for one-step submission https://juniperpublishers.com/online-submission.php 